\title{
PENGARUH KONSENTRASI SURFAKTAN CAMPURAN (SPAN 80 DAN SPAN 20) DAN RASIO VOLUME EMULSI/ FASA EKSTERNAL TERHADAP ESTRAKSI ION KADMIUM (Cd) MENGGUNAKAN TEKNIK EMULSI MEMBRAN CAIR
}

\author{
Effect of Mixed Surfactant Concentration (Span 80 and Span 20) and Volume Emulsion/External \\ Phase Ratio to Cadmium Ion (Cd) Extraction using Emulsion Liquid Membrane Technique
}

\author{
*Alif Hidayatullah Amin, Baharuddin Hamzah, dan Purnama Ningsih \\ Pendidikan Kimia/FKIP - Universitas Tadulako, Palu - Indonesia 94118
}

Received 03 December 2016, Revised 08 January 2017, Accepted 14 February 2017

\begin{abstract}
Research on the extraction of cadmium(II) ion has been performed using the emulsion liquid membrane technique. This research used laboratory experimental method using benzoyl acetone as carrier, kerosen as membrane, nitric acid solution as internal phase, span 80 and span 20 as surfactant, and cadmium(II) solution as sample. The present study was conducted to determine the optimum conditions of cadmium(II) ion extraction in solutions comprising variations in surfactant concentration of spans 80 and span 20 mixtures (1.5-3.5\%) and variations in the ratio of emulsion/external phase (1:5-1:7). Determination of remaining of cadmium(II) ion concentration in sample was analyzed using UV-Vis spectrophotometer at $519 \mathrm{~nm}$ wavelength. The results showed that the concentration of mixed surfactants (span 80 and span 20) which resulted in a maximum percent of extraction was 2.5\% with 60.11\% extraction percentage. In addition, the volume ratio of emulsion/external phase gave a maximum extraction percentage at a ratio of 1:5.5 with an extraction percent of $78.03 \%$.
\end{abstract}

Keywords: Cadmium(II) ion, emulsion liquid membrane, mixed surfactant, emulsion and external phase.

\section{Pendahuluan}

Indonesia merupakan negara yang memiliki pertumbuhan industri yang relatif pesat. Seiring berkembangnya industri dalam negeri, tidak hanya menimbulkan dampak positif bagi masyarakat, melainkan juga dampak negatif bagi lingkungan. Pencemaran lingkungan merupakan salah satu faktor rusaknya lingkungan yang akan memberikan dampak langsung ataupun tidak langsung pada ekosistem di dalamnya. Salah satu faktor pencemaran lingkungan disebabkan oleh kehadiran logam berat yang menjadi masalah yang cukup serius. Logam berat ini biasanya ditemukan dari hasil limbah industri. Sifat toksik logam berat, serta masuknya logam berat ke dalam air dapat mempengaruhi kualitas air maupun biota yang terdapat pada perairan (Purnomo, \& Muchyiddin 2007).

Limbah logam berat merupakan polutan yang berbahaya bagi makhluk hidup yang mengalami keterpaparan oleh unsur ini. Unsur logam berat memiliki kemampuan daya racun yang tinggi dan dapat terakumulasi pada jaringan tubuh makhuk hidup sehingga keberadaannya di lingkungan sangat tidak diiginkan. Salah satu contoh logam berat, yaitu logam kadmium (Cd) yang jika masuk ke dalam tubuh manusia dapat menyebabkan gangguan pada organ tubuh manusia (Yulianto, 2006).

Kadmium yang terdapat di dalam lingkungan pada kadar rendah berasal dari kegiatan penambangan seng $(\mathrm{Zn})$, timah $(\mathrm{Sn})$, kobalt $(\mathrm{Co})$, serta tembaga $(\mathrm{Cu})$. Sementara dalam kadar tinggi, kadmium

${ }^{*}$ Correspondence:

\section{Alif Hidayatullah Amin}

Program Studi Pendidikan Kimia, Fakultas Keguruan dan Ilmu Pendidikan, Universitas Tadulako

e-mail: alifhidayatullah21@gmail.com

Published by Universitas Tadulako 2018 berasal dari industri antara lain dari hasil sampingan penambangan, peleburan $\mathrm{Zn}$ dan $\mathrm{Pb}$. Hasil sampingan peleburan dan refining bijih $\mathrm{Zn}$ rata-rata memiliki kadar Cd sebesar 0,2-0,3\%. Sumber lain adalah dari penggunaan sisa lumpur kotor sebagai pupuk tanaman yang kemudian terbawa oleh aliran angin dan air (Widowati, dkk., 2008). Peningkatan kebutuhan logam berat sebagai material utama dalam proses produksi industri, maka perlu dikembangkan metode pemisahan dengan kinerja tinggi dan ekonomis untuk memperoleh kembali logam-logam dari proses industri tersebut. Oleh karena itu, perlu dilakukan pengolahan limbah cair terlebih dahulu sebelum limbah dibuang ke dalam lingkungan.

Pengolahan limbah cair umumnya dilakukan dengan cara pengendapan dan penyaringan. Namun cara-cara ini selalu menghasilkan limbah padat yang harus diolah lebih lanjut. Selain itu, pereaksi yang digunakan secara berlebihan akan menjadi polutan yang baru. Ekstraksi pelarut yang menggunakan tahap ekstraksi dan ekstraksi balik adalah alternatif yang lain, namun kurang efisien (Hamzah, dkk., 2013). Teknik pemisahan yang sedang dikembangkan adalah pemisahan dengan teknik membran cair yang didasarkan pada transpor ion logam melalui membran cair yang mengandung senyawa pembawa. Salah satu jenis pemisahan berdasarkan membran cair adalah teknik membran cair emulsi yang disebut juga membran cair bersurfaktan (Djunaidi \& Haris, 2003).

Teknik emulsi membran cair sangat selektif dalam memisahkan ion-ion logam, terutama dalam menentukan kondisi optimum ekstraksi suatu logam. Ekstraksi suatu logam menggunakan teknik emulsi membran cair dipengaruhi oleh beberapa faktor, diantaranya adalah konsentrasi larutan asam dalam fasa internal, konsentrasi zat pembawa, konsentrasi 
surfaktan, waktu ekstraksi, pH fasa eksternal, perbandingan volume emulsi dengan fasa eksternal, dan konsentrasi larutan sampel logam atau senyawa (Tuljannah, dkk., 2013). Hal ini sejalan dengan penelitian yang dilakukan Hidayah (2016) dengan menggunakan surfaktan campuran (span 80 dan span 20) sebagai emulgator dalam proses ekstraksi ion merkuri, dengan konsentrasi surfaktan campuran yang memberikan persen ekstraksi optimum adalah $2 \%$.

Pemilihan surfaktan didasarkan pada kesesuaian/kecocokan nilai HLB butuh dari fasa organik yang digunakan agar emulsi yang terbentuk dapat stabil dan tidak mudah pecah. Fasa organik yang digunakan pada penelitian ini berupa kerosen yang memiliki nilai HLB butuh adalah 6 untuk emulsi tipe W/O (Kloet \& Schra, 2002). Sementara itu, tidak ada surfaktan yang memiliki nilai HLB yang sama dengan kerosen. Oleh karena itu, digunakan surfaktan campuran dengan mengkombinasikan surfaktan yang mempunyai nilai HLB rendah (span 80 dengan nilai HLB 4,3) dan surfaktan yang mempunyai nilai HLB tinggi (span 20 dengan nilai HLB 8,6) yang memungkinkan untuk membuat campuran surfaktan yang mempunyai nilai HLB di tengah nilai HLB kedua surfaktan. Kemudian dengan melalui perhitungan diperoleh massa span 20 dan span 80 yang memiliki nilai HLB yang sesuai dengan nilai HLB butuh kerosen.

Tulisan ini bertujuan untuk mengurai kondisi optimum ekstraksi ion kadmium(II) dengan variabel yang digunakan adalah variasi konsentrasi surfaktan campuran (span 80 dan span 20) dan rasio volume emulsi/ fasa eksternal.

\section{Metode}

Alat yang digunakan pada penelitian ini adalah pipet tetes, gelas kimia, labu ukur, pipet volume, karet penghisap, neraca digital, corong pisah, statif dan klem, gelas ukur, spatula, batang pengaduk, wadah plastik, $\mathrm{pH}$ meter, cimarec stirring, hot plate, pengaduk magnetik, dan spektrofotometer UV-Vis Perkin Elmer Lambda 25. Sedangkan bahan yang digunakan pada penelitian ini adalah padatan $\mathrm{Cd}\left(\mathrm{NO}_{3}\right)_{2} \cdot 4 \mathrm{H}_{2} \mathrm{O}$ (Merck), padatan benzoil aseton (Merck), span-20 dan span-80 (Merck), kerosen, aquades, larutan asam nitrat $1 \mathrm{M}$ (Smart Lab), larutan $\mathrm{NaOH} 10 \%$ (Merck), dan larutan ditizon (Merck) dalam $\mathrm{CHCl}_{3}$ (Avantor).

\section{Pengaruh konsentrasi surfaktan campuran terhadap persen ekstraksi ion kadmium}

$30 \mathrm{~mL}$ emulsi ditambahkan ke dalam $150 \mathrm{~mL}$ larutan kadmium $10 \mathrm{ppm}$ dengan $\mathrm{pH}$ 2. Emulsi dibuat melalui pencampuran $15 \mathrm{~mL}$ fasa membran (mengandung 0,02 $\mathrm{M}$ benzoil aseton dan surfaktan campuran dengan konsentrasi surfaktan yang divariasikan, yaitu $1,5 \%, 2 \%, 2,5 \%, 3 \%$, dan $3,5 \%$ ) dan $15 \mathrm{~mL}$ fasa internal (mengandung larutan $\mathrm{HNO}_{3}$ $1 \mathrm{M})$ dengan kecepatan emulsifikasi menggunakan skala 10 magnetic stirer selama 10 menit. Proses ekstraksi dilakukan dengan kecepatan pengadukan pada skala 1,5 magnetic stirer selama 10 menit. Setelah ekstraksi, fasa eksternal dipisahkan dari emulsi dan diukur konsentrasi ion kadmium menggunakan spektrofotometer UV-VIS. Konsentrasi surfaktan yang akan digunakan untuk percobaan selanjutnya adalah konsentrasi surfaktan yang memberikan persen ekstraksi terbesar.

\section{Pengaruh Rasio Volume Emulsi/ Fasa Eksternal terhadap Persen Ekstraksi Ion Kadmium \\ Proses ekstraksi dilakukan sama seperti} perlakuan sebelumnya, tetapi menggunakan konsentrasi surfaktan campuran dengan hasil yang memberikan persen ekstraksi terbesar. Selain itu, rasio volume emulsi/ fasa eksternal yang divariasikan yaitu $1: 5 ; 1: 5,5 ; 1: 6 ; 1: 6,5$ dan $1: 7$.

\section{Analisis Kandungan Kadmium yang Tersisa pada Fasa Eksternal}

Sampel hasil ekstraksi dari masing-masing variabel diencerkan dengan aquades hingga pengenceran $10 \mathrm{kali}$. Sampel hasil pengenceran kemudian ditambahkan larutan $\mathrm{NaOH} 10 \%$ hingga larutan bersifat basa. Kemudian ditambahkan $10 \mathrm{~mL}$ larutan ditizon $0,001 \%$ dalam $\mathrm{CHCl}_{3}$ dan diaduk secara perlahan hingga diperoleh warna yang stabil. Fasa yang dianalisis merupakan fasa organik yang berwarna merah muda. Larutan standar $\mathrm{Cd}^{2+}$ yang digunakan terdiri dari beberapa konsentrasi, yaitu 0; 0,2; 0,4; 0,6; dan 0,8 ppm (Merck, 2010). Kemudian sampel dianalisis menggunakan alat spektrofotometer UV-VIS pada panjang gelombang maksimal yang diperoleh dari pengukuran larutan standar.

\section{Hasil dan Pembahasan}

\section{Pengukuran absorbansi larutan standar}

Reaksi antara ion $\mathrm{Cd}^{2+}$ dengan zat pengompleks ditizone $(\mathrm{HDz})$ menghasilkan senyawa kompleks kadmium ditizonat (Hasanpour, dkk., 2013) sesuai pada Gambar 1, yang berwarna merah muda dan dapat dianalisis secara spektrofotometri UV-Vis. Larutan kompleks yang diperoleh selanjutnya dianalisis menggunakan spektrofotometer UV-Vis pada panjang gelombang maksimum hasil pengukuran larutan standar. Larutan standar yang diukur untuk panjang gelombang maksimum adalah larutan $\mathrm{Cd}^{2+} 0,2 \mathrm{ppm}$. Panjang gelombang yang diukur adalah panjang gelombang yang berada pada range 500-560 nm karena merupakan daerah serapan untuk warna komplementer ungu kemerahan sampai merah muda (Khopkar, 2003). Hasil yang diperoleh menunjukkan bahwa pada panjang gelombang 519 $\mathrm{nm}$ terjadi penyerapan secara maksimal dari kompleks kadmium ditizonat yang berwarna merah muda dengan nilai absorbansi sebesar 0,190. Larutan yang dianalisis selanjutnya diukur pada panjang gelombang $519 \mathrm{~nm}$ untuk diperoleh konsentrasi dari sampel. Penentuan konsentrasi sampel nantinya akan didasarkan persamaan regresi dari deret absorbansi larutan standar. Hasil pengukuran absorbansi larutan standar dapat dilihat pada Tabel 1. 


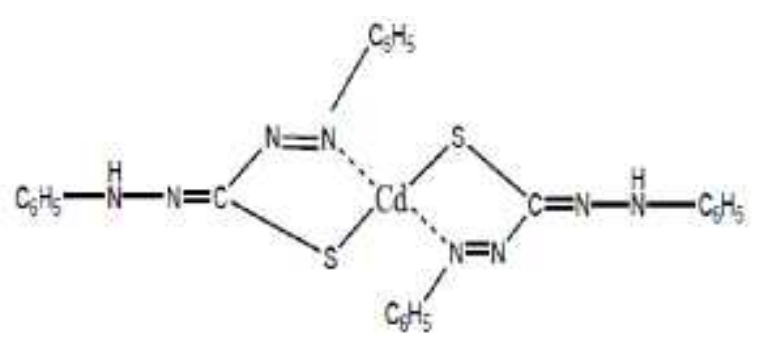

Gambar 1. Kompleks kadmium ditizonat

Tabel 1. Pengukuran absorbansi larutan standar $\mathrm{Cd}(\mathrm{II})$

\begin{tabular}{ccc}
\hline No & {$\left[\mathrm{Cd}^{2+}\right](\mathrm{ppm})$} & Absorbansi \\
\hline 1 & 0 & 0 \\
2 & 0,2 & 0,19 \\
3 & 0,4 & 0,373 \\
4 & 0,6 & 0,564 \\
5 & 0,8 & 0,605 \\
\hline
\end{tabular}

\section{Pengaruh konsentrasi surfaktan campuran terhadap} persen ekstraksi ion kadmium(II)

Percobaan ini bertujuan untuk mempelajari pengaruh konsentrasi surfaktan campuran yang memberikan persen ekstraksi optimum terhadap ekstraksi ion kadmium. Berdasarkan hasil percobaan diperoleh kurva hubungan konsentrasi surfaktan campuran terhadap persen ekstraksi ion kadmium sesuai pada Gambar 2. Kurva pada Gambar 2 menunjukkan bahwa konsentrasi surfaktan campuran $2,5 \%$ (b/v) merupakan konsentrasi optimum yang menghasilkan emulsi paling stabil dengan persen ekstraksi yang dihasilkan sebesar 60,11\%. Pada kondisi itu, tidak terjadi transfer fasa eksternal ke fasa membran atau sebaliknya yang menyebabkan pemisahan fasa eksternal dapat terpisah dengan sempurna terhadap fasa membran. Dengan demikian, maka kestabilan membran relatif baik dibandingkan kondisi yang lain (Nurhajalit, dkk., 1999).

Persen ekstraksi ion kadmium meningkat dengan bertambahnya konsentrasi surfaktan campuran dalam fasa membran, yaitu dari 1,5\% hingga 2,5\%. Pada konsentrasi surfaktan campuran $1,5-2 \%$ emulsi yang terbentuk kurang stabil sehingga persen ekstraksi yang dihasilkan kecil, dan meningkat pada saat konsentrasi surfaktan campuran dinaikkan menjadi $2,5 \%$. Hal ini disebabkan karena konsentrasi surfaktan dapat menurunkan tegangan permukaan antara air dan kerosen. Dengan semakin meningkatnya konsentrasi surfaktan dalam fasa membran, maka tegangan permukaan juga turun, akan tetapi apabila konsentrasi surfaktan terlalu banyak dalam fasa membran, maka dapat menyebabkan meningkatnya viskositas/kekentalan emulsi sehingga dapat memperlambat difusi kompleks dalam fasa membran dan berpengaruh terhadap efisiensi pemisahan pada penggunaan emulsi (Gawronski \& Religa, 2007). Idealnya diinginkan suatu emulsi yang stabil dengan kekentalan yang sekecil mungkin, karena semakin kecil pemecahan emulsi maka semakin stabil pula emulsi tersebut (Hamzah, dkk., 2011).

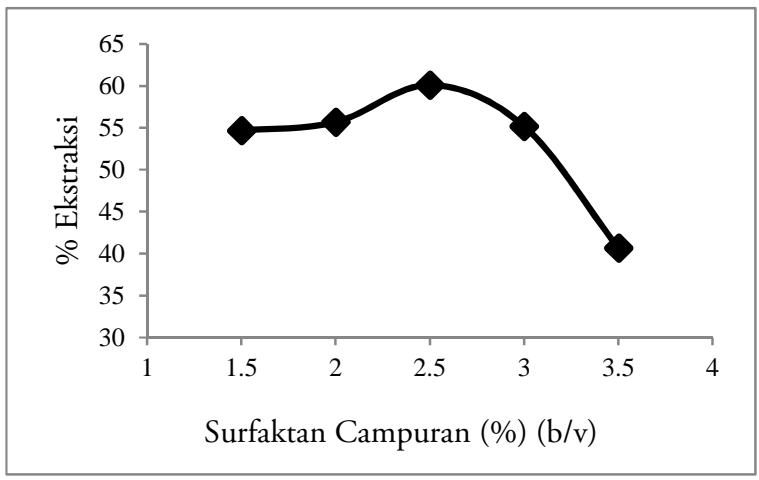

Gambar 2. Pengaruh konsentrasi surfaktan campuran terhadap persen ekstraksi Cd(II)

\section{Pengaruh rasio volume emulsil fasa eksternal terhadap persen ekstraksi ion kadmium(II)}

Pengujian ini bertujuan untuk menentukan jumlah fasa eksternal yang dapat ditampung oleh fasa internal yang terdapat di dalam emulsi. Berdasarkan hasil percobaan diperoleh data persen ekstraksi ion kadmium dengan variasi pengaruh rasio volume emulsi/ fasa eksternal terhadap persen ekstraksi ditunjukkan pada Gambar 3. Kurva pada Gambar 3 menunjukkan bahwa rasio $\mathrm{V}_{\mathrm{em}}: \mathrm{V}_{\mathrm{eks}}$ dari 1:5 hingga 1:5,5 mengalami peningkatan persen ekstraksi, sedangkan pada rasio $V_{\text {em }}: V_{\text {eks }}$ di atas 1:5,5 mengalami penurunan, sehingga dapat disimpulkan bahwa semakin banyak volume fasa eksternal yang digunakan, maka semakin kecil persen ekstraksi yang dihasilkan. Perbedaan persen ekstraksi yang diperoleh ini dapat disebabkan karena pada dasarnya rasio Vem : Veks dapat meningkatkan laju ekstraksi.

Perbandingan fasa eksternal yang lebih kecil dari kondisi optimum, yaitu 1:5, emulsi kurang terdispersi di fasa eksternal dan permukaan fasa eksternal tertutup oleh emulsi sehingga luas permukaan berkurang dan laju ekstraksi lebih lambat dan berakibat pada persen ekstraksi yang dihasilkan lebih kecil (Santoso, dkk., 2007). Namun, pada saat rasio $V_{\text {em }}: V_{\text {eks }}$ yang lebih besar dari 1:5,5 ternyata mengalami penurunan persen ekstraksi ion kadmium. Hal ini disebabkan karena fasa internal yang terdapat dalam emulsi memiliki kapasitas yang terbatas untuk menampung ion kadmium. Emulsi pada keadaan ini jumlahnya tetap, sedangkan fasa eksternal jumlahnya bertambah berdasarkan variasi rasio volume emulsi dan fasa eksternal sehingga dapat dikatakan bahwa jumlah fasa internal dalam emulsi tidak cukup untuk menampung seluruh ion kadmium yang terdapat dalam fasa eksternal. Pada rasio $V_{\text {em }}: V_{\text {eks }}$ 1:5,5 emulsi terdispersi dengan baik di fasa eksternal. Seluruh butiran emulsi tersebar merata sehingga menjadikan permukaan membran luas. Selain itu, pada kondisi tersebut ion kadmium telah mencapai keadaan setimbangnya di dalam fasa internal sebelum seluruh ion kadmium berpindah dari fasa eksternal ke fasa 
internal. Karena pada dasarnya dengan bertambahnya volume emulsi, fenomena penggembungan menjadi lebih cepat yang berakibat pada peningkatan pemecahan emulsi dan persen ekstraksi akan berkurang (Hamzah, 2010)

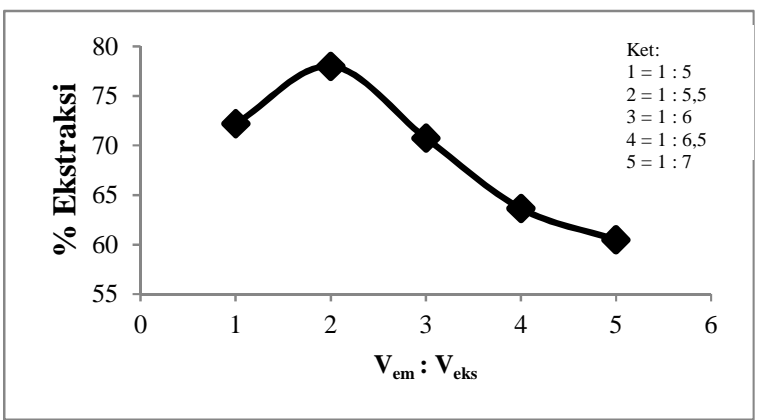

Gambar 3. Pengaruh $V_{\text {em }}: V_{\text {eks }}$ terhadap persen ekstraksi Cd(II)

\section{Kesimpulan}

Berdasarkan hasil penelitian menunjukkan bahwa kondisi optimum pada esktraksi ion kadmium dengan menggunakan teknik emulsi membran cair diperoleh pada konsentrasi surfaktan campuran 2,5\% dengan persen esktraksi sebesar $60,11 \%$. Sedangkan rasio volume emulsi/ fasa eksternal yang menghasilkan persen ekstraksi optimum, yaitu pada rasio volume emulsi/ fasa eksternal 1:5,5 dengan persen esktraksi sebesar 78,03\%.

\section{Ucapan Terima kasih}

Ucapan terima kasih penulis sampaikan kepada Ibu Husnia Muchtar selaku laboran Laboratorium Kimia FKIP UNTAD, yang telah membantu dalam menyelesaikan penelitian ini.

\section{Referensi}

Djunaidi, C., \& Haris, A. (2003). Pemisahan logam berat menggunakan membran cair berpendukung dengan variabel konsentrasi ion logam dan ph fasa umpan. Jurnal Kimia Sains dan Aplikasi, 6(2), 11-17.

Gawronski, R. \& Religa, P. (2007). Transport mechanism of chromium(iii) through the unmixed bulk liquid membrane containing dinonylnaphthalenesulphonic acid as a carrier. Journal of Membrane Science, 289(2), 187-190.

Hamzah, B. (2010). Aplikasi 1-fenil-3-metil-4-benzoilpirazolon sebagai pembawa kation pada ekstraksi ion tembaga(ii) menggunakan teknik emulsi membran cair. Makassar: Disertasi Doktor Universitas Hasanuddin.
Hamzah, B., Pulukadang, S. H., \& Hardani, R. (2013). Sintesis estraktan pirazolon dan uji kestabilan emulsi untuk ekstraksi ion raksa(ii) menggunakan teknik emulsi membran cair. PMIPA FKIP UNTAD: Prosiding Seminar Nasional Sains dan Matematika II.

Hamzah, B., Jalaluddin N., Wahab, A. W., \& Upe, A. (2011). T Pengaruh ion kadmium (ii) dan nikel (ii) pada ekstraksi ion tembaga (ii) dengan ekstraktan 4-benzoil-1-fenil-3-metil-2-pirazolin5-on menggunakan emulsi membran cair. Jurnal Natur Indonesia, 13(3), 269-275.

Hasanpour, F., Taei, M., Alimirzaei, Z., Karimi, H., \& Samimi R. (2013). Cloud point extraction and spectrophotometric determination of cadmium in some vegetables. Iran Jurnal Analytical Chemistry, 1(2), 44-29.

Hidayah, N. (2016). Pengaruh konsentrasi surfaktan dan perbandingan volume emulsi dengan volume fasa eksternal pada ekstraksi ion merkuri menggunakan teknik emulsi membran cair. Skripsi. Palu: FKIP Universitas Tadulako.

Khopkar, S. M. (2003). Konsep dasar kimia analitik. Jakarta: UI Press.

Kloet, J. V., \& Schra, L. L. (2002). The effect of shear and oil/water ratio on the required hlb for emulsification. Journal of Surfactants and Detergents, 5(1), 19-24.

Merck, E. (2010). The testing of water. Federal Republic of Germany: Darmstadt.

Nurhajalit, D. W., Prayitno, \& Kismolo, E. (1999). Ekstraksi ion krom dalam asam nitrat dengan teknologi membran cair untuk limbah industri penyamakan kulit. Puslitbang Teknologi Maju BATAN, 15(2), 3-12.

Purnomo, T., \& Muchyiddin, M. (2007). Analisis kandungan timbal (pb) pada ikan bandeng (chanos chans. f) di tambak kecamatan gresik. Neptunus, 14(1), 68-77.

Santoso, I., Buchari, B., Amran, M. B., \& Sulaeman, A. (2007). Ekstraksi dan pemisahan penisilin $\mathrm{g}$ dari fenilasetat dengan teknik membran cair emulsi. Jurnal Matematika dan Sains, 12(3), 9101.

Tuljannah, N., Hamzah, B., \& Diharnaini. (2013). Ekstraksi ion tembaga(II) dengan emulsi membran cair menggunakan ditizon sebagai pembawa kation. Jurnal Akademika Kimia, 2(2), 76-81.

Widowati, W., Sastiono, A., \& Jusuf, R. (2008). Efek toksik logam. Yogyakarta: Andi Offset.

Yulianto, B. (2006). Tingkat pencemaran logam berat di pantai utara jawa tengah. Semarang: BALITBANG. 